\title{
Špela Virant
}

\section{Tihi Don Juan. Koncept ljubezni in umetnosti v delih Maxa Frischa}

\author{
Ključne besede: Max Frisch, Stiller, Don Juan ali Ljubezen do geometrije
}

Frischeva igra Don Juan ali Ljubezen do geometrije je bila prvič uprizorjena in natisnjena leta 1953, torej leto prej kot roman Stiller, tik preden je Frisch v kritičnih srednjih letih zapustil družino in arhitekturo ter se povsem posvetil pisateljevanju. $\mathrm{V}$ Sloveniji so igro prvič uprizorili v Slovenskem narodnem gledališču v Ljubljani leta 1993 v režiji Barbare Hieng Samobor, ki jo je tudi prevedla. Žal prevod doslej ni izšel v knjižni izdaji.

Omenjena igra, ki jo je J. H. Petersen dobrih petindvajset let po prvi uprizoritvi označil za »morda najboljšo igro « Maxa Frischa (Petersen, 1979, 41), je manj politična kot tiste, ki so $\mathrm{v}$ času nastanka zbudile veliko pozornosti v nemškem govornem prostoru. Čeprav v igri Don Juan podobno kot v znameniti igri Andorra (1961) obravnava problematiko identitete, ga tu še ne zanimajo politične razsežnosti te problematike, temveč predvsem njen pomen $\mathrm{v}$ okviru zasebnega - ljubezenskega in ustvarjalnega - življenja posameznika.

Med svojim prvim bivanjem v Ameriki je Frisch začel pisati roman $\mathrm{z}$ delovnim naslovom Kaj počnete $z$ ljubeznijo (Was macht ihr mit der Liebe), vendar je to delo začasno opustil in začel pisati igro Don Juan. Iz začetega romana je kasneje nastal roman Stiller. Tako ni presenetljivo, da lahko med igro in romanom odkrijemo vzporednice, na katere so različni avtorji opozorili že v sedemdesetih letih 20. stoletja, torej v času, ko se je nemška literarna veda $\mathrm{z}$ analizo del Maxa Frischa najbolj intenzivno ukvarjala (Jurgensen, 1976, 46; Kieser, Starr Guilloton, 1979, 262).

Podobno kot roman Stiller bi se ta igra lahko začela s stavkom: »Jaz nisem don Juan« (Kieser, Starr Guilloton, 1979, 262). Frischa zanima proces, kako Andri postane Jud v Andorri, kako James Larkin White postane Stiller in kako Janezek, ki ima rad matematiko, postane gospod Janez, bolj znan kot Juan ali Giovanni. Čeprav je pri vseh teh likih jasno, da jih družbene okoliščine silijo v določeno vlogo, pa nihče od njih ni nikakršen Kaspar Hauser, nepopisan list brez lastnega značaja. Prav nasprotno: njihov značaj jih žene $\mathrm{v}$ zaplete, $\mathrm{v}$ katerih so poraženi - če smemo tako poimenovati skupek strahov, dvomov in trmoglavega vztrajanja pri takšnih ali drugačnih načelih. Najbolj 
očitno to kaže Frischev don Juan, ki ga zanimata le geometrija in morda še šah, ki ga igra v bordelu, skratka to, kar je po občem prepričanju kar najbolj oddaljeno od ljubezni do žensk in vseh $\mathrm{z}$ njo povezanih aktivnosti.

$\mathrm{Na}$ predvečer dogovorjene in politično zaželene poroke prestrašeni Juan pobegne $\mathrm{v}$ temačni, samotni park, kjer sreča svojo prav tako prestrašeno nevesto dono Anno. Zaljubita se, ne da bi se prepoznala. Naslednjega jutra se Juan noče poročiti z Anno, čeprav v njej zdaj prepozna svojo nočno ljubimko. Če sta se oba zmožna v noči pred poroko ljubiti z neznancem, potem ne more zaupati ne $\mathrm{v}$ njeno ne v svojo ljubezen.

Juanova ljubezen do geometrije je tako psihološko utemeljena: v njenem hladnem, logično urejenem svetu išče zatočišče pred nejasnostjo, nepredvidljivostjo ter protislovnostjo čustev in strasti. Seveda poskus, da bi si po racionalnih, matematičnih načelih uredil življenje, spodleti. Frisch nato pospeši dogajanje in na način lahkotne bulvarke Juana hitro popelje skozi ključne dogodke, podobne tistim, ki jih poznamo iz iger Tirsa de Moline, Molièra in Mozartovega libretista Da Ponta. V zmedi, ki nastane, Juan zakrivi smrt Anninega očeta, posredno pa še smrt svojega očeta, neveste in najboljšega prijatelja. $\mathrm{V}$ tej zmešnjavi naleti na različne dobrosrčne ženske, ki ga hočejo rešiti. Juan to dopusti in iz tega nastane podoba zapeljivca, ki ženske pahne $\mathrm{v}$ sramoto, moške pa v pogubo.

Zadnji dve dejanji igre, sestavljene iz konvencionalnih petih dejanj, ki jih dopolnjujejo intermezzi, kažeta don Juana nekaj let kasneje. Zdaj je star triintrideset let, zapeljal je že mnogo žensk, preprosto zato, da bi zadovoljil njihova pričakovanja ter posledično razžalil in pogubil mnogo moških. Ta vloga ga utesnjuje, hudo pa ga pestijo tudi dolgovi. Da bi se znebil obojega, torej vloge in dolgov, skuje načrt. Pred izbranim občinstvom namerava med slavnostno pojedino uprizoriti svoj spektakularni odhod v pekel. Najame igralca, ki naj bi igral kamnitega gosta - torej nagrobnik seviljskega komturja. Skupaj z njim naj bi se potem pogreznil v klet. Cerkev bi to lahko interpretirala kot kazen za grehe, $\mathrm{v}$ zameno pa bi odplačala njegove dolgove in ga sprejela v samostan, kjer bi se končno v miru posvetil geometriji.

Načrt se zaradi maščevalnosti enega od prevaranih mož le delno posreči. Juan sicer pobegne, kupčija s cerkvijo pa spodleti. V stiski sprejme ponudbo bogate vdove in se skupaj $\mathrm{z}$ njo naseli $\mathrm{v}$ njeni graščini, medtem ko vsi mislijo, da je res končal $\mathrm{v}$ peklu.

Juan ni srečen. V graščini se počuti kot ujetnik - ne sme se pokazati v javnosti. Razmerje z bogato vdovo je težavno. Gre za nekdanjo prostitutko Mirando, ki se je nekoč zaljubila vanj prav zato, ker je bil drugačen, ker ni hotel, kar hočejo vsi moški v bordelu. Z njo ne more, brez nje pa tudi ne. Med njima so napetosti, vendar se nikoli ne 
sporečeta. Oba tiho trpita, ker drug drugega ne moreta osrečiti. Vzajemno zamolčano nesrečo ob koncu zapečati podatek o njeni nosečnosti.

Frisch se je zavedal, da zgodba, ki jo je napletel, kjer vsi mislijo, da je Juan v peklu, on pa živi v razmeroma nesrečnem zakonu, vodi v interpretacije, ki zakon enačijo $\mathrm{s}$ peklom, zato je prehitel interprete in ob koncu igre škofu, ki je na obisku pri Juanu in Mirandi, pripisal repliko, ki takšno razlago ovrže, češ da je banalna (Frisch, 1962, 78). Ne gre torej ne za sekularizacijo pekla ne za demoniziranje zakona. Don Juanov zakon je povsem človeški in zelo vsakdanji. To je že dovolj hudo. Vanj ga niso pahnile ne božje ne peklenske sile, ampak se je vanj zapletel sam, v njem pa ga držijo seveda finance, odgovornost za otroka, družbene vloge in nenazadnje ljubezen. Največja težava Juana in Mirande je nezmožnost komunikacije, ki po eni strani izvira iz jezika, ki ni tako logičen in nedvoumen kot matematični simboli, po drugi strani pa iz čustev, ki so tako mešana in nejasna, da jih tudi $\mathrm{z}$ matematičnimi simboli ne bi bilo mogoče urediti.

Če je ambivalentnost čustev in jezika osrednji problem ljubezenskega razmerja vigri Don Juan ali Ljubezen do geometrije, pa Frisch v romanu Stiller bolj podrobno razgradi še vrsto drugih problemov, povezanih z ljubezenskim in ustvarjalnim življenjem.

Tudi v romanu kipar Anatol Ludwig Stiller ne beži le pred svojo družbeno vlogo, ampak tudi pred ženskami, pred ženo in ljubico. Zlasti pred ženo, ki jo zapusti, ko se ona, obolela za tuberkulozo, bori za življenje. Ko se Stiller po šestih letih spet vrne v Švico, se njegov boj z lastno identiteto navidezno vsaj približno srečno konča. Tik preden ga sodišče dokončno obsodi na samega sebe, se tudi sam spravi s sabo. Spet postane Stiller, čeprav ne več kipar, spet zaživi skupaj z ženo Juliko in spet zakon ni srečen. Bolezen se povrne in Julika umre.

Podobno kot Frischev don Juan tudi Stiller najbolj trpi, ker ljubi, vendar ta ljubezen ni dovolj, da bi bila ljubljena žena srečna.

Vzporedno z zgodbo Stillerja in Julike nam roman pripoveduje še zgodbo o nič manj zapletenem, a manj nesrečnem zakonu njunih prijateljev Sibylle in Rolfa. Vzporejanje teh dveh zakonov Frischu omogoči, da se z različnih vidikov poglobi $\mathrm{v}$ problematiko zakonskih odnosov in tematizira vprašanja zvestobe, prevare, svobode, ljubosumja, tolerance, enakopravnosti, vzajemne odvisnosti partnerjev, komunikacije, vedenjskih vzorcev itd. Pogosto ponavlja in variira motiv podobe. Svetopisemsko prepoved izdelovanja rezane podobe poveže na eni strani s kiparstvom, ki se mu Stiller odpove v korist umetne obrti, na drugi strani pa $\mathrm{z}$ odnosi med partnerjema. Frisch pokaže, kako hitro si partnerja ustvarita podobo drug o drugem, kako težko je to enkrat ustvarjeno podobo spremeniti in kako težko je sploh zaznati vse, kar se z njo ne sklada. Podoba utesnjuje, duši in v skrajni konsekvenci onemogoči živ odnos. 
Tematizacija zakonske zveze upravičuje rabo krščanskih motivov, kot sta pekel in prepoved podobe, saj je krščanska cerkev stoletja bdela nad institucijo zakona, vendar Frisch ne problematizira niti vloge cerkve pri reguliranju te institucije niti internaliziranja njenih predpisov. Tudi brez pomoči cerkve ljudje v zakon prinašajo dovolj problemov, da napolnijo roman in igro. Vendar pa se Frisch teološki problematiki ne more povsem izmakniti, vsaj ne v igri, kjer si za osrednji lik izbere don Juana in se odloči, da bo obdržal vse ključne elemente, ki jih pozna literarna tradicija. Konstitutivni element tega lika je poleg zapeljevanja tudi hibris, predrzni napuh, ki izziva bogove.

Frisch ohrani tudi ta element. Ob koncu tretjega dejanja, ko spozna, da se je še enkrat zmotil, ko je preoblečeno Mirando imel za svojo nevesto, se odpove krščanskemu obredju in žalovanju ter izreče izzivalne stavke: »Zdaj se ničesar več ne bojim. Bomo videli, kdo bo koga imel za norca, nebesa mene ali jaz njih!« (Frisch, 1962, 51).

Frischev don Juan najprej obilno greši, ne da bi pri tem kaj prida užival, nato pa se norčuje iz nebeških in peklenskih sil, ko uprizori kaznovanje in odhod v pekel. Nič od tega ne izzove bogov, da bi posegli v dogajanje in Juana zares kaznovali. Upravičeno bi torej sklepali, da jih ni ter da stari sistem grehov in kazni ni več v veljavi. Vendar pa Juana kljub temu doleti nesreča v obliki tihega trpljenja v zakonski zvezi, Stillerja, ki je v primerjavi z Juanom grešil manj, pa še večja nesreča, ko mu umre ljubljena žena. Zdi se torej, da sta Juan in Stiller vendarle kaznovana, vprašanje pa je, za kaj? Kaj je njun greh, ali - bolje rečeno - tragična zmota ali pa - še bolje rečeno - profana napaka?

Stiller in Juan ne verjameta v boga. Herta Franz $(1976,238)$ ugotavlja, da je Juan boga nadomestil z geometrijo, Hiltrud Gnüg $(1976,230)$ pa v njem vidi »modernega (reflektiranega) skeptika«. Oba protagonista sicer res živita v svetu brez bogov, vendar se nista odpovedala konceptu absolutnega. Oba ta božji atribut preneseta na ljubezen, ki mora biti absolutna, nezmotljiva in vsemogočna ali pa je ni. Trpljenje v zakonu je pri takšni substituciji vnaprej programirano. Še večja je napaka, očitna zlasti pri Stillerju, ko gre za opredelitev lastne vloge v takšni religiji ljubezni.

Stiller trpi, ko vidi, da njegova mlada žena živi za umetnost, za balet, da torej ni popolnoma in izključno predana njuni ljubezni, ki potemtakem ni absolutna in ne more biti prava. Kakor v igri, tako tudi tu očitki ne zadenejo le ženske, ampak tudi njega samega in mu zbudijo občutek nezadostnosti. To pride še bolj do izraza, ko Julika zboli. Zdaj se ne čuti odgovornega le za njeno srečo, temveč tudi za njeno zdravje in življenje. Pripisuje si vlogo odrešenika, ki ji seveda ne more zadostiti in zato pobegne tudi pred tistim delom odgovornosti, ki bi ga kot navaden smrtnik lahko prevzel.

Hibris Frischevega don Juana in Stillerja ni v kršenju božjih zapovedi - tistih o prešuštvu, ubijanju in izdelovanju podobe -, temveč v dosti hujšem prestopku, saj 
poskušata $\mathrm{v}$ kontekstu ljubezenskega razmerja sama zasesti božjo pozicijo. Ker to ni mogoče, mesto absolutnega boga, ki bi kot zunanja referenčna točka lahko deloval kot medij ljubezni, pa je izpraznjeno, se ljubezen zdi odčarana, ljubimca pa prepuščena samemu sebi in drug drugemu.

Sprijaznjenje s svojo identiteto za oba pomeni tudi sprijaznjenje $\mathrm{z}$ lastno človeškostjo, ki pač ni nezmotljiva in vsemogočna. Krhka in ranljiva ni izpostavljena le omejitvam, ki so lastnoročno delo posameznika in skupnosti, v katero je vpet, temveč tudi neobvladljivosti lastne narave. Don Juanu se kaže kot spolna privlačnost, ki se ji ne more upreti in ki vodi v spočetje otroka, ${ }^{1}$ Stillerju pa kot bolezen in smrt, ki je ne more preprečiti.

Edini prostor, kjer te omejitve ne veljajo, torej edini prostor nesmrtnosti, je literatura. Tudi škof, ki v zadnjem dejanju igre obišče don Juana, mu ne ponuja nič drugega, ko mu izroči knjižico, ki naj bi jo napisal Tirso de Molina.

To je iztočnica, ki Frischu omogoči, da v zadnje dejanje integrira refleksije o literaturi in gledališču. Opozarja na dva problema. Prvi je neobvladljivost literature. Don Juan hoče sam uprizoriti svoj konec ter tako ustvariti in nadzorovati mit o don Juanu, vendar mu to spolzi iz rok. Literarni junak zaživi po svoje in Juan ga ne more obvarovati pred morebitno neustrezno instrumentalizacijo. Kot je opozorila že Mojca Kranjc, se lik don Juana pojavi že v Frischevi zgodnejši igri Kitajski zid, kjer se pritožuje nad svojim poreklom iz pekla literature in nad vsem, kar so mu že napesnili (Kranjc, 1993, 234). V igri, v kateri je sam glavni junak, se Juan pritožuje predvsem nad verzijo Tirsa de Moline, ki se mu zdi vse preveč pobožna, vendar se kaj hitro distancira $\mathrm{z}$ ironijo: »Bog žegnaj vaš obed!« (Frisch, 1962, 78).

Drugi problem, ki ga Frisch obravnava v tej igri in ki ga najavlja že naslov, kjer se don Juan kot literarna tvorba sooča $z$ geometrijo, je problem jezika. Jezik je pogosto dvoumen in nelogičen, a pri izražanju čustev nič bolj uspešen kot matematični simboli. Za izražanja resnice pa mu škof - ki v zadnjem dejanju nastopa kot posrednik med tem svetom in svetom literature - kljub vsemu pripiše večjo možnost za uspeh, vendar le, če ga uporabimo za ustvarjanje fikcije. Fikcija, bodisi literarna ali gledališka, lahko posreduje resnico. Ali kakor pravi: »Resnice ni mogoče pokazati, lahko si jo le izmislimo« (Frisch, 1962, 77).

Igra o don Juanu sicer kaže, kako iz resničnosti nastaja literatura, vendar se, prav zato, ker išče resnico procesa literarizacije, zapira nazaj v zgodbo, v zgodbo o Janezku, ki je imel rad geometrijo.

1 »Bis zum Verbluten ausgesetzt dem andern Geschlecht» (Frisch, 1962, 76). 
Frisch pa ne bi bil Frisch, če zgodbe o don Juanu ne bi potujil. Igro je sicer označil kot komedijo in v njej predvidel uporabo vseh gledaliških sredstev, ki obetajo odrski spektakel, od zmešnjav in zamenjav do preoblek, mask in posebnih učinkov, vendar je prav tako razigran pri mešanju različnih žanrov, saj je uporabil elemente komedije nravi in tipizacije, psihološko poglobljenega razvoja figur, bulvarke in metateatra. $\mathrm{V}$ začetku petdesetih let 20. stoletja je bilo to gotovo pogumna ustvarjalna gesta, ki lahko tudi uprizoritvi omogoči realizacijo potujitvenih učinkov in avtorefleksijo gledališča. Frischeve ubeseditvene strategije tu seveda spominjajo na strategije postmodernističnih besedil, vendar je njihov deklarirani namen še vedno iskanje načinov za posredovanje resnice, o kateri moderni skeptik morda dvomi, je pa dokončno nikoli ne zavrže.

Podobno pogumno je Frisch tudi v romanu Stiller uporabil različna pripovedna sredstva in se poigraval z žanri. Roman bi lahko označili kot razvojni ali kot ljubezenski roman, roman o nazadovanju umetnika in propadu ljubezni. Poleg tega se Frisch poigrava s pripovedno perspektivo.

Pripovedovalec prvega, obsežnejšega dela je Stiller oziroma White. White v priporu, kamor je zašel, ko so na švicarski meji ugotovili, da je njegov potni list ponarejen, od odvetnika dobi zvezke, v katere naj bi zapisal svojo zgodbo. Ob pisanju se počasi približuje Stillerju. Ko ga obsodijo na samega sebe in se končno sprijazni z identiteto Stillerja, umolkne, vlogo pripovedovalca pa prevzame državni tožilec. Ta menjava pripovedovalca nekoliko spominja na Goethejevega Wertherja, kjer v trenutku, ko Wertherjeva pisma postanejo zmedena in nepovezana, pripovedovanje prevzame fiktivni urednik, ki pisma komentira in opiše Wertherjev konec. Seveda bi lahko Frisch vlogo pripovedovalca podelil le tožilcu, vendar ga, podobno kot je Goetheja zanimala pot, ki je Wertherja prignala v samomor, zanima Stillerjevo doživljanje procesa, ki vodi v molk. Goethe je uvedel novega pripovedovalca, da je opisal Wertherjevo smrt, Frisch pa, da bi uokviril in poudaril Stillerjev molk, ki s tem, da mu je prej pustil do besede, lahko pride bolj do izraza.

Stillerjevi zapiski iz pripora ne podajo sklenjene zgodbe, ampak razpadejo v labirint raznorodnih pripovedi, ki obsegajo preproste opise aktualnih dogodkov, anekdote, kratke zgodbice, esejistična razmišljanja in opise narave ter se spet vrnejo k opisom dogodkov, vseskozi pa se prepletajo z razmišljanji o Stillerju. Ta disperzna pripoved sicer Stillerja pripelje k sprejemanju samega sebe, a tudi k molku. Zdi se, da lahko o Stillerju razmišlja in piše, dokler je White, dokler se upira temu, da bi bil avtor svoje lastne zgodbe. Avtorstvo velike zgodbe namreč vse preveč spominja na vsevednega vsemogočnega in je zato tudi neke vrste hibris. Stiller poskuša hibris odpraviti v ljubezni, kiparstvu in v besedilu, zato takšno avtorstvo razpusti v zapisovanje majhnih pripovedi, v rokodelstvo, dokler povsem ne utihne. 
Frischevi junaki sicer res živijo v svetu brez boga, otepajo pa se z njegovo senco, ki se je zajedla globoko v njihove miselne strukture in vedenjske vzorce. Frischevi junaki, kot so don Juan, Stiller in kasneje Walter Faber, kažejo, da se ni težko odpovedati bogu, če na mesto absolutnega, vsevednega in vsemogočnega postavijo geometrijo, znanost in tehniko ali pa umetnost in ljubezen. Moderna tragičnost teh figur je, da se sicer soočajo z zmotnostjo takšne substitucije, vendar se v svojem mišljenju in vedenju ne morejo odpovedati konceptu absolutnega. Vsi trije uberejo lažjo pot in opustijo umetnost, znanost in tehniko ter pobegnejo pred ljubeznijo. Naj bo to trma ali uvid, kar jim otežuje vračanje $\mathrm{v}$ stari način življenja, dokončno pa to vračanje preprečijo okoliščine časa, v katerem so nastanjeni. Vsekakor sta jim opuščanje in beg bolj sprejemljiva kot vračanje na staro in bolj dosegljiva kot revidiranje načinov mišljenja, ki se podrejajo absolutnemu in resnici, ter posledično revidiranje pojmovanja znanosti, umetnosti in ljubezni.

K sreči pa Frisch ni Stiller in z njim ni obmolknil, temveč je nadaljeval s pisanjem in prizadevanji v procesu neizbežnega revidiranja pojmovanja teh bistvenih človekovih dejavnosti, ki tudi v začetku 21. stoletja še ni končan.

\section{Literatura}

Franz, H., Der Intellektuelle in Max Frischs Don Juan und Homo faber, v: Über Max Frisch II (ur. Schmitz, W.), Frankfurt na Majni 1976, str. 234-244.

Frisch, M., Stiller, Ljubljana 2011.

Frisch, M., Stücke 2, Frankfurt na Majni 1962.

Gnüg, H., Das Ende eines Mythos: May Frischs Don Juan oder Die Liebe zur Geometrie, v: Über Max Frisch II (ur. Schmitz, W.), Frankfurt na Majni 1976, str. 220-233.

Jurgensen, M., Max Frisch. Die Dramen, Bern, München 1976.

Kieser, R., Starr Guilloton, D., Faustische Elemente in Max Frischs Don Juan oder Die Liebe zur Geometrie, v: Max Frisch. Aspekte des Bühnenwerks (ur. Knapp, G. P.), Bern, Frankfurt na Majni, Las Vegas 1979, str. 255-274.

Kranjc, M., Prihajam iz pekla literature, v: Max Frisch. Don Juan ali Ljubezen do geometrije. Gledališki list Drame SNG 72, 9, Ljubljana 1993, str. 234-235.

Petersen, J. H., Frischs dramaturgische Konzeptionen, v: Max Frisch. Aspekte des Bühnenwerks (ur. Knapp, G. P.), Bern, Frankfurt na Majni, Las Vegas 1979, str. 27-58. 


\section{Špela Virant}

\section{The silent Don Juan. The concepts of love and art in the works of Max Frisch}

Keywords: Max Frisch, "Stiller”, "Don Juan or The Love of Geometry”

In the novel Stiller and in the play Don Juan, both published in the early 1950s, Frisch already focuses on the problem of identity as one of his major themes, but it is not yet situated in a political context as, for example, in the play Andorra. In these works, the identity-problem is situated in the domain of intimate relationships and artistic creativity, offering the possibility to discuss Frisch's concepts of art and love, which unfold through Frisch's treatment of the traditional literary figure of Don Juan and his hubris. Frisch's Stiller and Don Juan do not believe in God; but their frame of mind stays the same, while the position of God and his attributes are assigned to love, art and geometry. Although both literary figures in the course of events realize that this substitution is a mistake, they are unable to alter their concepts of love and art. Instead of altering the concepts, they rather resign in silence, while Max Frisch continues to search for alternatives in reflecting on the process of fictionalization and in developing innovative narrative and dramatic structures. 